\title{
A Study on the Factors Influencing the Usage of Environmentally Friendly Products
}

\section{Nicole Elise Esposito, Halliburton Energy Services}

Nicole is currently a design engineer for Halliburton Energy Services in the Testing and Subsea department. She completed her bachelor's degree in mechanical engineering from Texas A\&M University in August 2011. She then went on to complete her master's degree in mechanical engineering from Texas A\&M in December 2012 under Dr. Julie Linsey.

Dr. Vimal Viswanathan, Tuskegee University

Dr. Vimal Viswanathan is an assistant professor in the Department of Mechanical Engineering at Tuskegee University, AL. He obtained his PhD in Mechanical Engineering from Texas A\&M University in 2012.

His research interests include design theory \& methodology, design creativity and engineering education.

Dr. Julie S Linsey, Georgia Institute of Technology 


\section{A Study on the Factors Influencing the Usage of Environmentally Friendly Products}

\section{$\underline{\text { Abstract }}$}

Designing engineering systems to minimize their environmental impact is a very complex task. Little exists to guide designers in developing products that are integrated into users' lives thus reducing the overall environmental impact at the system level. A better understanding of user behavior will allow this knowledge to be better integrated into more complex, system level models. As an initial step, this paper seeks an experimental framework to identify important parameters to be measured. For many products, the use stage is where most environmental damage occurs. The factors that may influence or obstruct a person to behave in a proenvironmental way are complicated. It is critical to train our future designers on those factors to reduce environmental impact caused by engineered systems. This paper reports an experiment that tests alternative products to disposable plastic water bottles to answer several eco-friendly design questions. The experiment determines whether certain eco-friendly products are more successful than others are and why this may be the case. This research includes the testing of four different products. Student participants receive one product each to use for a one-week testing period and then return to complete two questionnaires. Surveys measure the success of the product and the level of environmental consciousness through various scales. With the understanding of various factors influencing the market success of environmentally friendly products, a set of guidelines for the design of such products can be developed.

\section{$\underline{\text { Introduction }}$}

The care of our environment is an ever-growing topic among people today and some choose to act upon this concern, while others remain doubtful. Whatever the case may be, the push for a more eco-conscious society is evident everywhere. Recently, more eco-friendly alternatives to products have become more widely available to consumers. A certain pressure has been placed on designers to produce products that are friendlier to the world we all live in. Sauer and Ruttinger ${ }^{1}$ also comment that, "While environmental friendliness of a product alone is certainly no guarantee for commercial success, research has indicated that ecological criteria are important to the decision-making process of consumers.” It is important for designers and our future engineers to understand that they can make a substantial difference in the world, just by considering environmental implications in their designs.

While it is true that designers have a great opportunity to make a difference, it is important for them to understand the psychology behind people and their interactions with the environment. Environmental psychology is complex and the factors that may influence or obstruct a person to behave in a pro-environmental way are complicated. A brief background on environmental psychology along with the relevant research pertaining to design for the environment is presented later in this paper.

While there are many different types of pro-environmental behaviors such as recycling, using an alternative form of transportation to reduce pollution, and supporting environmental legislation, this research will focus on the pro-environmental behavior of using eco-friendly products. The problem exists that environmentally friendly products are still not widely accepted and used by 
consumers. There may be many reasons as to why this is the case. A common complaint of consumers is that they believe the quality and functionality of eco-friendly products are not acceptable compared to their non eco-friendly counterparts ${ }^{2}$. Another possibility is that people may have psychological barriers that prevent them in taking the necessary steps to take action ${ }^{3}$. This paper takes the view that many other factors are likely to influence users' acceptance.

This research will analyze several products and attempt to determine the factors that influence their use with consumers. With these factors, certain design principles relevant to eco-friendly design can be developed. Product designers will be able to use these design principles to create eco-friendly products that consumers enjoy and are more willing to use in their daily lives. More importantly, these principles can be included in our design courses so that our future generation of engineers can create more environmentally friendly engineering systems.

\section{$\underline{\text { Background }}$}

\section{Environmental Psychology}

The study of environmental psychology is an important research topic within the field of psychology and deals with the interactions between people and their environment. It has been a widely researched topic, but only recently has this science been applied to engineering design. As stated previously, a possible reason why people do not accept eco-friendly products is because they have psychological barriers that prevent them from even taking the first steps to using the product. People are unaware of the problem, unsure of what to do, do not trust experts on climate change, think the problem does not apply to them, are fixed in their ways, or believe their actions will not make a difference ${ }^{3}$. Whatever the case may be, in order for a person to lead a more eco-friendly life, they must learn to break their environment damaging habits and change their behaviors.

The motivation to change behaviors can be influenced by many psychological drivers such as needs, wants, goals, values, ideologies, beliefs, attitudes, worldviews, perceptions of prescriptive and cultural norms, and identification to nature ${ }^{3}$. A very large amount of research addresses influencers of pro-environmental behavior and there has been debate over whether a positive environmental attitude leads to pro-environmental behaviors. One side claims that people who have pro-environmental attitudes will thus exhibit pro-environmental behaviors such as recycling and using eco-friendly products. Therefore, to create more eco-conscious people in the world, we should change their attitude toward the environment. This theory seems very logical, but is a quite outdated theory. Current research opposes this idea and claims that often there is a disconnect between our attitudes and behaviors. This is referred to as the "value-action gap" 4 . So if there is a gap between attitudes and behaviors, how do we get people to change their behaviors? Many theories attempt to explain this phenomenon and give solutions to fix the problem.

There have been numerous models that describe the discretion between environmental awareness and actually displaying pro-environmental behavior. A few of these models include early US linear models, altruism, empathy and pro-social models, and sociological models ${ }^{5}$. It can be concluded from these various theories and models that pro-environmental behavior is influenced by many factors. The psychology behind a person's decision-making is very complex and many 
times not logical; so it is difficult to explain exactly why a person behaves as he/she does. Even though the process of decision-making is complicated, there is a model developed by Dhalstrand and Biel that describes a systematic process to changing poor environmental habits into proenvironmental habits ${ }^{6}$. They propose a series of sub-steps in behavior change so that a person with a strongly established habit which is detrimental to the environment may develop a new habit that is more beneficial to the environment. The steps include activation, attending present behavior, considering alternative solutions, planning new behavior, testing new behavior, and establishing new behavior. The results from their experiment demonstrate that an important first step in behavior change is to realize that we should be responsible for our actions and exhibit behaviors to protect the world we all live in. Once this realization is achieved, people may be motivated in the process of changing their behaviors. Another important finding is that when a new behavior is being tested and evaluated, the specific beliefs relating to the product determines whether a new pro-environmental behavior forms ${ }^{6}$.

\section{Designing for Behavior Change}

Today, a substantial opportunity exists for designers to make a positive impact on the world. Fuad-Luke ${ }^{7}$ emphasizes the importance of designers by claiming, "Designers actually have more potential to slow environmental degradation than economists, politicians, businesses and even environmentalists.” Designers must concentrate on the use stage of a product's life cycle because most of the environmental damage occurs there as a result of poor user behaviors ${ }^{8,9}$. Fortunately, research has shown that user behavior can be influenced through product design ${ }^{10}$.

Sauer and Ruttinger ${ }^{1}$ argue that poor behaviors during the use stage result from mismatches between the user, product, and task. A functional problem occurs between the task and the product so that the product does not contain the ecological features for the task. An efficiency problem exists between the user and the product because the user does not know how to operate an ecological feature on the product. The mismatch between the user and the task is known as an effectiveness problem, which means the user does not know how to perform a task in an ecological manner ${ }^{1}$. Elias et al. ${ }^{8}$ describe three strategies to increase the energy efficiency of products used in the home. The first is consumer education where the user has access to information about the environmental effect of the product on our environment and he/she understands how to use it efficiently. The second strategy is product feedback, which provides information to the user about energy consumption of the device, thus prompting the user to change their behaviors accordingly. The final strategy is user-centered design, which analyzes user behaviors and ergonomics to ensure that the product is used more efficiently ${ }^{8}$.

A possible tool to aid designers in eliminating these environmentally erroneous behaviors is the Design with Intent tool (DwI). This tool aids designers in developing eco-friendly products that influence user behavior ${ }^{11}$. This method incorporates many of the theories described by psychologists as well as designers from diverse backgrounds and translates them into applicable design techniques. There are several "lenses" that correspond to the various views on behavior change, and include architectural, error proofing, interaction, ludic, perceptual, cognitive, Machiavellian, and security designs. These eight lenses help the designer to evaluate their design problem from many different perspectives other than the ones they are typically accustomed to, thus leading to a greater variety of solutions ${ }^{11}$. 
Interaction design has become an important research topic in the world of environmental design and has mostly been incorporated in the computer science industry, and is slowly being introduced to product design. Here, the product-user interactions are studied so that the user's poor environmental behaviors can be identified. Once these behaviors are identified, the product designer can develop interfaces within the product to lessen the chance that these poor behaviors will occur. Oberender et al. ${ }^{10}$ illustrate this process through the redesign of a vacuum cleaner. First, the environmentally relevant erroneous behaviors are found using the error-types and errorcauses-matrix as well as Eco-FMEA. A redesign of the vacuum cleaner is then developed so that it includes a feedback device and the users consume the minimum amount of electricity while vacuuming.

Another product developed to increase user awareness about electricity consumption is the Power Aware Cord ${ }^{12}$. An important topic in eco-friendly product design is the awareness of electricity we use every day. Electricity is sometimes a hard concept to grasp for people, especially since it is invisible. Due to this, the creators of the Power Aware Cord have developed a product that allows users visualize the electricity flow from their devices. The cord contains electroluminescent wires that glow when energy is passing through it and the intensity of the light changes as the amount of energy changes. The designers of this product hope that the visual feedback display of energy will help to change user's energy consumption behaviors ${ }^{12}$.

Applying these principles of environmental psychology on product design, designers can develop eco-friendly products that are also widely accepted by consumers. The following sections briefly describe research pertaining to the topic of designing for behavior change.

\section{Method}

For this experiment, four eco-friendly alternatives for disposable plastic water bottles were chosen and tested by participants. Each participant was given one product to test for one week. After this one week of use, they completed two surveys: one product evaluation survey and one demographics survey.

\section{Research Questions}

The experiment presented in this paper is a pilot study and is exploratory in nature. The study addresses the following research questions:

1. Are there some eco-friendly products that people are more willing to use than others?

2. If so, which products are more successful / accepted?

3. Why are some products more successful than others?

4. Will the participants be less motivated to use the eco-friendly products if they require more user activities?

5. Does a positive attitude toward the environment mean that the participants are more likely to change their behavior and accept the product? 
6. Is the product habit changing?

7. Which features are successful and which are unsuccessful?

The questionnaires and the environmentally friendly products for the experiment were carefully chosen to answer these research questions. The process for choosing the appropriate products is detailed in the following sections.

\section{Products}

The first step in this experiment was to select a popular base product with significant environmental impact and had a variety of environmentally friendly alternatives. After considering many options, a disposable water bottle was selected as the reference product. A variety of alternative products that served the same function in a more environmentally friendly manner were considered further. There were eight total products found. An activity diagram was created for each of the eight products as well as one for a typical disposable water bottle. A list of product features was also developed that included eight characteristics: easy set-up, easy maintenance, short operation time, refillable, long filter life, indicates filter change, low cost, and all-inclusive. The descriptions for each of these features are described below:

Easy Set-up: The product should be easy and fast to set up before use.

Easy Maintenance: The product should be easy to clean and not require frequent filter changes.

Short Time to Operate: The time to filter water should be fast and there should not be many processes to operate the product on a daily basis.

Refillable: The product should be able to be refilled throughout the day so that the user can have clean filtered water all day.

Long Filter life: If the product has a filter, it should have a long filter life so they do not have to replace it frequently.

Indicates Filter Change: The product should alert the user when the filter needs to be changed.

Low Cost: The cost of the product should be low. The replacement filter cost may also need to be considered.

All-Inclusive: The products should be all inclusive so that they do not require additional products to function.

The table comparing each product with a plastic disposable water bottle is shown in Table 1 with the products selected highlighted. The final four products selected for the experiment were: the Brita filtration water bottle, the 321 water bottle, the Botl filter, and the Filtrete water station. Each product was unique with its own set of features. The only product that satisfied all the criteria was the Brita water bottle. For a full experiment, having multiple products which varied on features of interests would allow regression analysis to be used to determine which products features influenced product usage/acceptance and to estimate the effect size. 
Table 1. Comparison of each product based on product features

\begin{tabular}{|c|c|c|c|c|c|c|c|c|}
\hline \multirow[b]{2}{*}{ PRODUCTS } & \multicolumn{8}{|c|}{ FEATURES } \\
\hline & Easy set-up & \begin{tabular}{|l|} 
Easy \\
Maintenance
\end{tabular} & \begin{tabular}{|l} 
Short \\
Operation \\
Time \\
\end{tabular} & $\begin{array}{l}\text { Can Refill } \\
\text { Bottle } \\
\text { throughout day }\end{array}$ & \begin{tabular}{|l|} 
Long \\
Filter Life \\
\end{tabular} & \begin{tabular}{|l} 
Indicates \\
Filter Change
\end{tabular} & Low Cost & All-Inclusive \\
\hline Filtrete Water Station & & & & & $\mathbf{x}$ & $\mathbf{x}$ & & $\mathbf{x}$ \\
\hline Botl Filter & $x$ & & $x$ & $x$ & & & $x$ & \\
\hline Brita Water Bottle & $x$ & $\mathrm{x}$ & $\mathbf{x}$ & $x$ & $\mathrm{x}$ & $\mathrm{x}^{*}$ & $\mathrm{x}$ & $\mathrm{x}$ \\
\hline Metal Water Bottle & $x$ & $x$ & $x$ & & $\mathrm{n} / \mathrm{a}$ & $\mathrm{n} / \mathrm{a}$ & $x$ & \\
\hline Filter Straw & $x$ & $\mathrm{x}$ & $x$ & $x$ & $x$ & & $x$ & \\
\hline 321 Water Bottle & & & & $x$ & $\mathrm{x}$ & & & $x$ \\
\hline Faucet Filter & & $\mathrm{x}$ & $\mathrm{x}$ & & $\mathrm{x}$ & $\mathrm{x}$ & & \\
\hline Filter Water Pitcher & $x$ & $x$ & $x$ & & $x$ & $x$ & $x$ & \\
\hline Disposable Bottle & $x$ & $x$ & $x$ & & $\mathrm{n} / \mathrm{a}$ & $n / a$ & $x$ & $x$ \\
\hline
\end{tabular}

* indicates that the person can sign up for filter change warnings online

The process of selecting the products for the study included examination of all the product activity diagrams along with the table of product features. In choosing the appropriate products to test, the main concern was that the products needed to have features and user activities that differed greatly from each other and from the disposable bottle. The products were purposefully selected to be distinct so that the participants could test a wide variety of product features and activities. Each product used in the experiment is described below.

The first product presented in Figure 1a is the 321 water bottle. This product is set-up by inserting the filter at the end of the blue plastic piece in the center of the bottle. The filtration system mimics a French press and works by filling the bottle with water and then pushing the plunger slowly through the entire length of the bottle. Once this has been done, the water is ready to drink. When the bottle is empty, the user must remove the plunger and repeat the filtration process. As the 321 water bottle has an internal plunger system, the cleaning and maintenance may seem complex and lengthy to the user. In addition, the time it takes to filter the water is long because the plunger must be pushed slowly to avoid breaking the thin plastic rod.

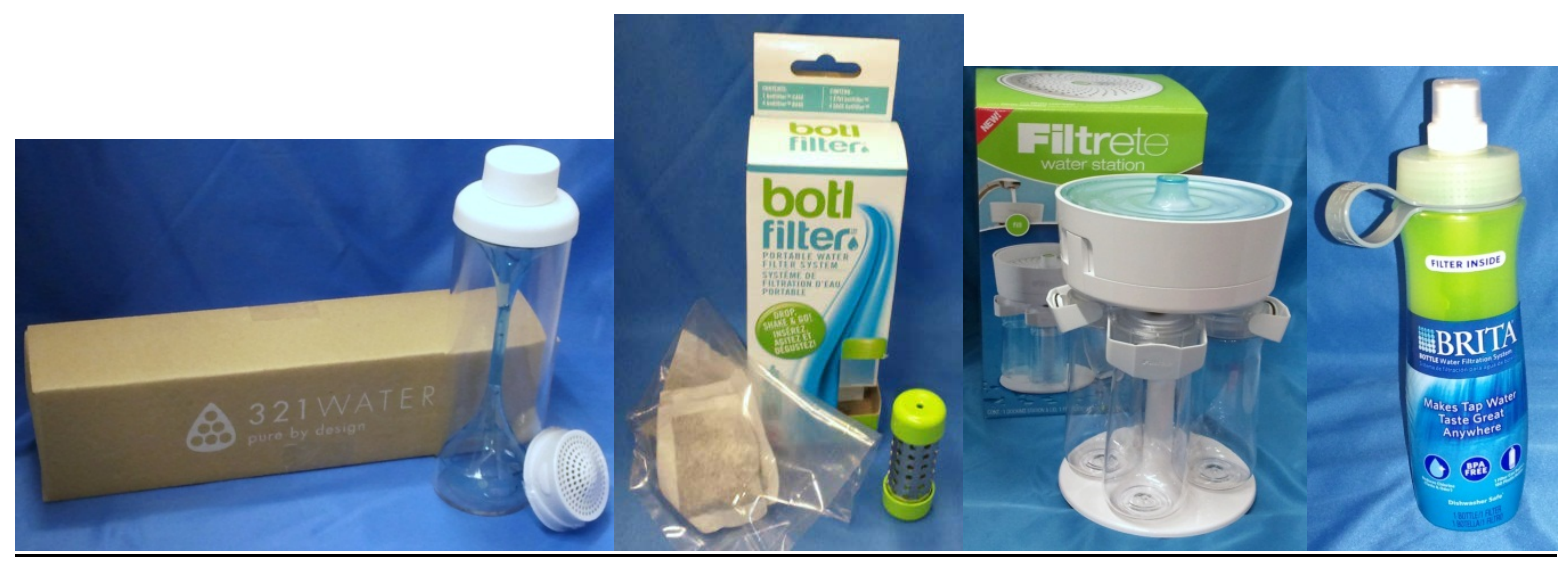

Figure 1. (a) Picture of the 321 water bottle. (b) Picture of the botl filter. (c) Picture of the Filtrete water station. (d) Picture of the Brita water bottle.

The second product presented in Figure $1 \mathrm{~b}$ is the Botl filter. This product consists of a small metal tube with holes and two plastic end caps that are removable. As shown in the image, this product comes with small filtration bags, which are inserted into the metal tube. Once the user 
inserts the bag and closes the tube with both end caps, the Botl filter is simply placed in a water bottle of their choice. The bottle is then filled with water and shaken several times. A disadvantage to this product is that it is not all-inclusive since an additional product (a water bottle) must be used in conjunction with the Botl filter. In addition, a single filtration bag should be replaced every three days, which is a very short filter life. This means that the user must purchase filter bags regularly to continue using the product. Benefits to this product are easy setup and short operation time.

The next product shown in Figure 1c is the Filtrete water station. This product consists of a stand that holds four water bottles and a basin on top that holds a water filter. Once the product is assembled, the user must place the water station under a faucet and fill the basin until the water bottles are full. A disadvantage to this product is that once users take bottles with them, say to work or school, they cannot refill the bottle with filtered water if they are away from the water station system.

The final product used in this experiment is the Brita filtration water bottle and is shown in Figure 1d. This product is simple to operate and takes a relatively short time to operate on a daily basis. After the product is initially set-up, the user just needs to fill the bottle with tap water and screw on the cap. To drink, the user must squeeze the bottle to push the water through the filter and out the nozzle. The Brita water bottle is the only product that has all the product features described earlier, though the bottle itself does not remind the user to change the filter but they can sign up for reminders online.

\section{Participants}

The sample size for the experiment was 11, all between 20-33 years of age. All participants were engineering students attending Texas A\&M. The participants were recruited through their senior level engineering design class and were offered class credit as compensation. The participants were also allowed to keep the product they tested.

\section{Procedure}

Each student took home one product to test for one week. After using the product, they returned and completed two surveys. A product evaluation survey was given to them for the product they tested to measure success of the product along with many other variables. An additional survey measured several demographic variables as well as environmental consciousness. Environmental behavior was measured through the use of the Ecological Attitude Scale (EAS) and attitude toward the environment was measured with the New Environmental Paradigm Scale (NEP).

\section{Questionnaires}

The first survey given to the participants was the product evaluation survey, which determined product success through asking questions about the participants' weeklong experience with the product. This survey was designed to determine whether certain products were more successful, why this may be the case, and whether the product was habit changing. The first few questions asked whether they would recommend the product to a friend or family member, whether they would continue to use the product, and what they would rate the product on a 1-7 scale. The "total success score” was created by adding all three responses together. The participants were 
also asked whether they typically used plastic disposable bottles and if they thought the product they tested would change their habit. A few specific questions were asked to determine whether the set-up and maintenance of the product were difficult. These two features are thought to affect the success of the product. The end of the questionnaire included a few short answer questions. They were asked to describe what they liked most and least about the product and to explain why. These questions were asked to determine the specific features that the participants considered successful and unsuccessful. Another important question asked was whether the product influenced them to become more eco-friendly in other aspects of their life.

The second survey measured environmental consciousness with the use of the New Environmental Paradigm Scale or $\mathrm{NEP}^{13}$ and the Ecological Attitude Scale or EAS ${ }^{14}$. Environmental attitude was part one of the survey, and was determined using the 15 Likert item NEP scale. The participants were given a series of statements about the environment and were asked if they strongly agree, mildly agree, are unsure, mildly disagree, or strongly disagree. Environmental behavior was part two on the survey, and was calculated using the 30 true/false items in the EAS scale. Part three of the survey was a single question used to evaluate selfdesignated environmental consciousness. The question was stated, "All things considered, would you classify yourself as an environmentalist?" In part four, questions were asked to measure the participants' willingness to make life-style changes because of environmental problems. There were nine life-style changes given and the participants were asked if they did those, willing to do those, reluctant to do those, or even opposed to do those. The questions from part three and four were based on the research of Krause ${ }^{15}$. It was expected that the environmental attitude would moderate the use of the products and participants' opinions about them.

\section{$\underline{\text { Results and Discussion }}$}

The results of this pilot experiment demonstrate the basic experimental design and measures are effective for pursuing an understanding of how product design influences user acceptance and use of environmentally friendly products. The results also indicate that a number of unexpected important factors for this particular set of products also influence the outcomes. The detailed results are provided in the following sub-sections.

\section{Lessons learned}

Many issues in the experimental design became known after analyzing the data from the initial pilot experiment. The most important realization is that there were many more variables than anticipated that influence user behavior for even a simple product as water filtration system and many were unaccounted for in the experimental design. This became apparent in the product evaluation survey. The participants were asked to record what they liked most and least about the product on the open-ended part of the survey.

There were many features that were not measured in the experiment, therefore they are not being controlled for. Factors such as aesthetics, bottle design, and lid design are examples of these extraneous variables and are likely affecting participants' opinion of the product greatly (Table 2). This is an unanticipated result of the experiment, and a simple solution can be implemented so that many of the variables are controlled. The solution is to change the products that are tested and keep the water bottle consistent in all conditions of the experiment. This way, the aesthetics, 
bottle design, lid design, and size are controlled. For future experiments, the same water bottle will be given to the participants for all the conditions, and the method of filtration will vary in each condition. The water station and 321 water bottle will be removed from the experiment and replaced with the Brita faucet filter and the Brita filter pitcher.

Table 2. Positive and Negative Features of Products

\begin{tabular}{|l|l|}
\hline Positive product features & Negative product features \\
\hline Portable & Lid design \\
\hline Aesthetics & Aesthetics \\
\hline Multiple bottles & Bottle design \\
\hline Quick to use & Poor filtration \\
\hline Easy installation & Difficult installation \\
\hline Size & Size \\
\hline
\end{tabular}

In addition to changing the products, it was decided that all the participants recruited for the experiment should typically use disposable bottles as a main source of their drinking water. In the first pilot, only three of the eleven participants reported that they typically use disposable plastic water bottles. An important part of this study is to determine whether the new product changes their habit of using disposable bottles. In order to measure this, all participants must typically use disposable bottles.

In addition, an independent variable, operation time, will be added to the product evaluation survey. This is because the time to operate each product on a daily basis is different for each product and may affect whether the user accepts the new product in exchange for disposable plastic water bottles.

\section{Attitude Hypothesis Results}

For the attitude hypothesis, it is assumed that a positive environmental attitude leads to proenvironmental behavior. For the statistical analysis, a logistic regression is performed with one dependent variable (participants' recommendation, their continuing use, their rating, and the number of uses) at a time and the independent variable of environmental attitude. If the users continue to use the product and their rating of the product were both significantly related to their attitude. 
Table 3. Regression analysis results for attitude

\begin{tabular}{|l|l|l|}
\hline Dependent Variable & Chi-Square & p-value \\
\hline Recommendation & 13.34 & 0.75 \\
\hline Continue to use & 11.37 & 0.11 \\
\hline Rating & 17.25 & 0.24 \\
\hline Number of uses & 20.16 & 0.51 \\
\hline
\end{tabular}

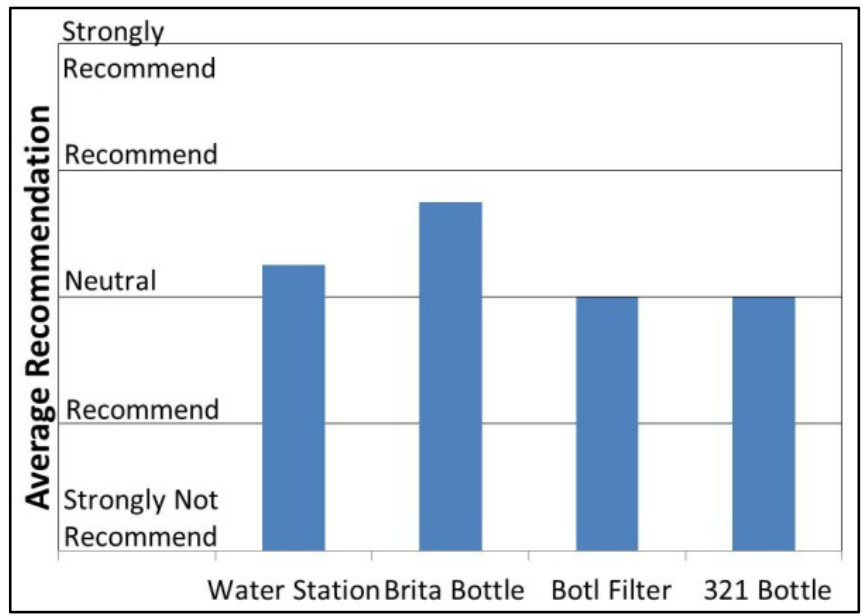

Figure 2. Average recommendations from participants

For the activity hypothesis, it is assumed that difficulty of product set-up and difficulty of product cleaning/maintenance affect the participants' overall opinion of the product and whether they accept it. The same regression analysis has been done with the other two independent variables: set-up difficulty and cleaning/maintenance difficulty (Table 4). There is significance between set-up difficulty with rating, set-up difficulty with total success, and set-up difficulty with number of uses. Based on the regression results, there may be a relation between difficulty of product set-up and the participants' overall opinion of the product, as well as how often they use the product. No significant effects are seen for maintenance difficulty. Based on the results for maintenance difficulty, the difficulty of cleaning or maintaining the product has little or no effect on the participants' opinion of the product.

Table 4. Regression analysis results for set-up difficulty

\begin{tabular}{|l|l|l|l|}
\hline Dependent Variable & Coefficient & Standard Error & p-value \\
\hline Recommendation & -0.44 & 0.65 & 0.51 \\
\hline Continue to use & -0.44 & 0.39 & 0.28 \\
\hline Rating & -1.44 & 0.39 & 0.00 \\
\hline Total Success & -2.33 & 0.90 & 0.03 \\
\hline Number of uses & -3.17 & 1.49 & 0.06 \\
\hline
\end{tabular}

In addition to performing a regression analysis, several graphs that compare each product help to determine whether there is a particular product that performs well or one that performs poorly. Figure 2 shows the average recommendation for each product. Overall, the participants do not recommend any of these products in particular. For a study like this, some of the products need to be recommended by participants and there needs to be variation on this measure. 
The participants are also asked to rate the product on a 1-7 scale where one is the best product they have ever used and seven is the worst. Similar to the product ratings, the average total success scores are about the same for all the products. This metric includes the scores from the product recommendation, continue to use the product, and the product rating questions. The average rating and average success scores are shown in Figure 3 and Figure 4 respectively. Again, these are the measures that products must vary on in order to derive solid conclusions. Also, the economic backgrounds of the participants vary which may affect their familiarity with different products. This may bias the outcome from this question.

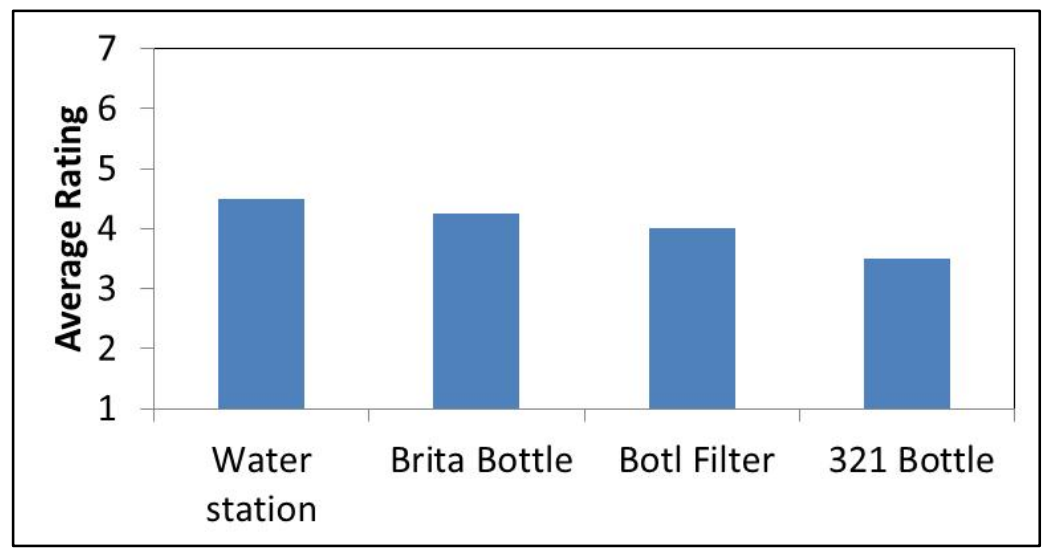

Figure 3. Average rating for each product

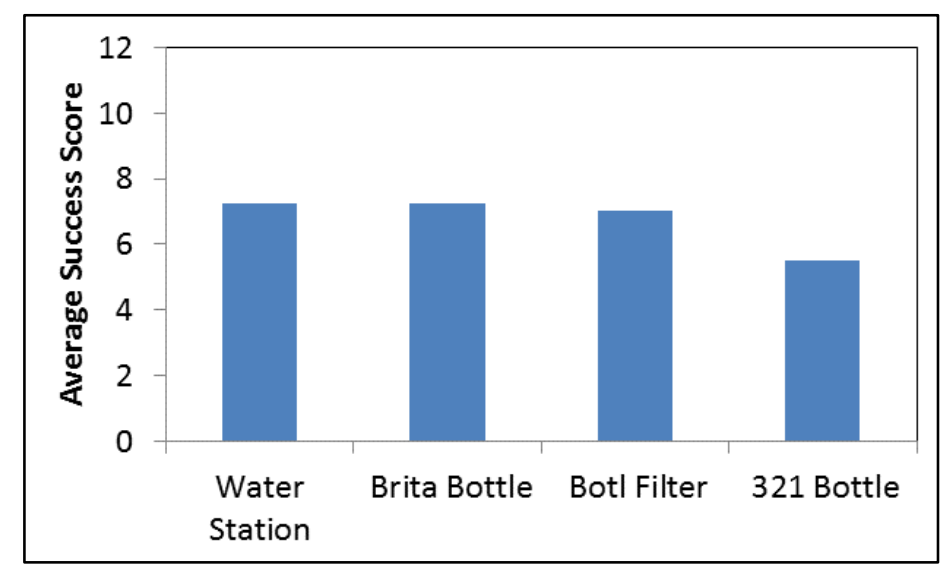

Figure 4. Average total success score

The participants were also asked to report how often they use the product in the week. Their options are 1-2 days, 3-4 days, 5-6 days, and daily. The result for the average number of uses for each product is given in Figure 5. From the results, it is clear that the 321 water bottle is not used as much as the other three products. This may be because the participants find it difficult to setup and use it on a daily basis.

Based on the results, the 321 water bottle scores consistently poorly on many of the comparisons and this is unexpected since one of this product's goals is to increase environmentally friendly behavior. One of the students reported that it is both difficult to set-up and difficult to clean/maintain. Another participant who tested the product reported that they do use disposable plastic water bottles, but this product may not change this habit. The Brita water bottle scores 
consistently well in all categories and is the only product to score one "strongly recommend" for the product recommendation question. This product is expected to do well because it possesses the entire list of positive product features described in Table 2.

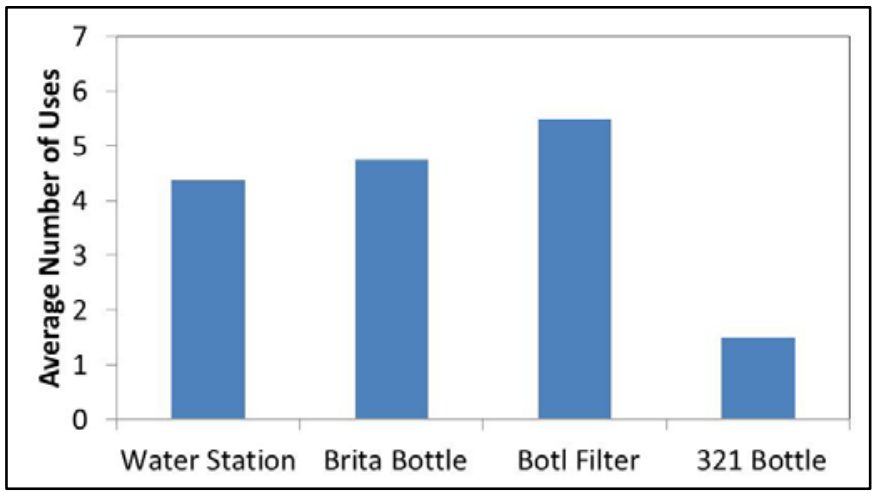

Figure 5. Average number of uses (in days) with error bars +/- 1 standard error

\section{$\underline{\text { Conclusions }}$}

Ultimately, product designers, especially novice designers and students, need to have an effective set of guidelines and quantitatively models to guide their design of consumer products such that the products reduce environmental impact. Little exists to guide designers in developing products that are both accepted by users and integrated into their lives and thus reduce the overall environmental impact at the system level. As an initial step, this paper seeks an experimental framework to identify important parameters to be measured to assisting in developing guidelines for product designers.

There are many lessons learned from this initial pilot experiment. The most important realization is that when testing eco-friendly alternatives to products, it is essential that many of the features of the eco-friendly alternative mimic the features of the non eco-friendly counterpart. In this study, features such as aesthetics, bottle design, and lid design affected the participants in a negative way. When the eco-friendly product resembles the non eco-friendly alternative as much as possible, the participants are less likely to be affected by these undesirable variables present in the products. This study also demonstrates that a number of factors influence eco-friendly product acceptance. Consistent with prior research, this study also demonstrates that environmental attitude is important. Initial product set-up and adding user activities may affect product acceptance also.

The sample sizes for this pilot experiment are very small, yet they produce many critical results. This shows that with a larger sample size, it is probable that the variables that are nearly significant may prove to be significant. This also shows that the effect size of these variables is very high and it is very likely that user behavior can be changed with suitable approaches to product design. If engineering students can be trained in such approaches, they can reduce the environmental impacts of the products through design. 


\section{$\underline{\text { Acknowledgements }}$}

The work presented in this paper was a part of Nicole Esposito’s Masters thesis at Texas A\&M University. During her time as a graduate student, her work was supported by the National Science Foundation Award Numbers CMMI-1000954 and DUE-0942400. Any opinions, findings, and conclusions or recommendations expressed in this paper are those of the authors and do not necessarily reflect the views of the National Science Foundation.

\section{$\underline{\text { References }}$}

[1] Sauer, J., and Rüttinger, B., "A new framework for the design of ecological domestic appliances: designcentred product development", Proceedings of the Human Factors and Ergonomics Society Annual Meeting: SAGE Publications, 2000, pp. 6-319-316-322.

[2] Esposito, N., and Linsey, J., "Principles of Green Design: Analysis of User Activities and Product Feedback", ASME International Design Engineering Technical Conferences, Chicago, IL, 2012.

[3] Swim, J., Clayton, S., Doherty, T., Gifford, R., Howard, G., Reser, J., Stern, P., and Weber, E.," Psychology and global climate change: Addressing a multi-faceted phenomenon and set of challenges. A report by the American Psychological Association's task force on the interface between psychology and global climate change", American Psychologist Vol. 66, No. 4, 2009, pp. 241-250.

[4] Darnton, A.," Driving Public Behaviours for Sustainable Lifestyles Report 2 of Desk Research commissioned by COI on behalf of DEFRA", Sustainable Development Unit of the Department for Environmental Food and Rural Affairs. The Government of United Kingdom, 2004.

[5] Kollmuss, A., and Agyeman, J.," Mind the gap: why do people act environmentally and what are the barriers to pro-environmental behavior?", Environmental education research Vol. 8, No. 3, 2002, pp. 239260.

[6] Dahlstrand, U., and Biel, A.," ProEnvironmental Habits: Propensity Levels in Behavioral Change1", Journal of Applied Social Psychology Vol. 27, No. 7, 1997, pp. 588-601.

[7] Fuad-Luke, A., "The eco-design handbook: a complete sourcebook for the home and office": Thames and Hudson, 2005.

[8] Elias, E.W., Dekoninck, E., and Culley, S.J.," Designing for 'use phase’energy losses of domestic products", Journal of Engineering Manufacture Vol. 223, No. 1, 2009, pp. 115-120.

[9] Tang, T., and Bhamra, T., "Understanding Consumer Behavior to Reduce Environmental Impacts through Sustainable Product Design", Design Research Society Conference, Sheffield, UK, 2008.

[10] Oberender, C., Weger, O., Birkhofer, H., and Sauer, J., "Ecological design for the usage phase: an interdisciplinary approach to design for environment", Environmentally Conscious Design and Inverse Manufacturing: Proceedings EcoDesign 2001: IEEE, 2001, pp. 71-76.

[11] Lockton, D., Harrison, D., Holley, T., and Stanton, N.A., "Influencing interaction: development of the design with intent method", proceedings of the 4th international conference on persuasive technology: ACM, 2009, pp. 5.

[12] Gustafsson, A., and Gyllenswärd, M., "The power-aware cord: energy awareness through ambient information display", CHI'05 extended abstracts on Human factors in computing systems: ACM, 2005, pp. 1423-1426.

[13] Dunlap, R.E., Van Liere, K.D., Mertig, A.G., and Jones, R.E.," New trends in measuring environmental attitudes: measuring endorsement of the new ecological paradigm: a revised NEP scale", Journal of social issues Vol. 56, No. 3, 2000, pp. 425-442.

[14] Maloney, M.P., Ward, M.P., and Braucht, G.N.," A revised scale for the measurement of ecological attitudes and knowledge", American psychologist Vol. 30, No. 7, 1975, pp. 787.

[15] Krause, D.," Environmental Consciousness An Empirical Study", Environment and Behavior Vol. 25, No. 1, 1993, pp. 126-142. 